\title{
RESEARCH OF THE $\mathrm{Fe}_{2} \mathrm{O}_{3}$ POWDER GRANULATION EFFECT ON $\mathrm{BaFe}_{12} \mathrm{O}_{19}$ FIRING TEMPERATURE
}

\author{
Iulian STEFAN ${ }^{1, a^{*}}$, Adrian OLEI ${ }^{2, b}$ and Claudiu NICOLICESCU ${ }^{3, \mathrm{c}}$ \\ ${ }^{1}$ University of Craiova, Faculty of Mechanics, Department of Engineering and Management of \\ Technological Systems, Drobeta Turnu Severin, Romania \\ ${ }^{2}$ University of Craiova, Faculty of Mechanics, Department of IMST, Turnu Severin, Romania \\ ${ }^{3}$ University of Craiova, Faculty of Mechanics, Department of IMST, Turnu Severin, Romania \\ astefan_iuly@yahoo.com, badrian_olei@yahoo.com, 'nicolicescu_claudiu@yahoo.com
}

Keywords: ferrites, milling, firing temperature

\begin{abstract}
In the paper is presented the study of the $\mathrm{Fe}_{2} \mathrm{O}_{3}$ powders granulation effect on the firing parameters for the $\mathrm{BaCO}_{3}+6 \mathrm{Fe}_{2} \mathrm{O}_{3}$ powder mixture. The $\mathrm{Fe}_{2} \mathrm{O}_{3}$ powders were milled in a ball mill in wet medium. The results indicated that the granulation of $\mathrm{Fe}_{2} \mathrm{O}_{3}$ powders decreased rapidly with the increase of milling time. The $\mathrm{Fe}_{2} \mathrm{O}_{3}$ milled powders were then mixed with unmilled barium carbonate powders in order to form barium hexaferrite. After mixing, the powders were analized by thermogravimetric point of view and then the obtained barium hexaferrite samples were investigated by XRD analysis.

It was observed that the firing temperature of the hexaferrites decreases with 10 degrees when we introduce in the mixture $\mathrm{Fe}_{2} \mathrm{O}_{3}$ milled powders with a fine granulation.
\end{abstract}

\section{Introduction}

M-type barium hexaferrites have been around for a long time. Interests in them have continued because new applications have been found for them. Their fabrication often requires the use of high sintering temperatures. Heating at too high of a temperature can, however, lead to destruction of the crystalline structure, while heating at too low of a temperature can result in incomplete solid-state reaction [1].

There are various alternative processes have been developed to prepare fine barium hexaferrite powders with the desired particle size characteristics. These techniques include chemical coprecipitation [2-6], glass crystallization [7], hydrothermal synthesis [8,9], sol-gel [10,11,12], microemulsion [13] and mechanochemical activation [14]. So, many of these methods lead to formation of intermediate phases such as $\mathrm{Fe}_{2} \mathrm{O}_{3}, \mathrm{BaCO}_{3}$ or $\mathrm{BaFe}_{2} \mathrm{O}_{4}$ together with barium hexaferrite which decrease the saturation magnetization compared to that prepared by ceramic routes. The classical ceramic method for the preparation of barium hexaferrite consists of firing mixture of iron oxide and barium carbonate at high temperature $\left(1100{ }^{\circ} \mathrm{C}\right)[15]$. This method has the advantages of low production cost and high production yield.

In this paper we present results for the $\mathrm{BaFe}_{12} \mathrm{O}_{19}$ samples, in which $\mathrm{Fe}_{2} \mathrm{O}_{3}$ was the subject of mechanical miling using a planetary ball mill.

The research conducted in this paper shows the influence of powders particle morphology used in forming of homogeneous mixtures on the formation reactions of barium hexaferrite.

It is known that the speed of the reaction is mainly determined by the reactivity of the components that come into contact in their heating. So, their reactivity is determined by the fineness of the powder particles and the number of point contacts between the particles.

In the case of barium hexaferrite are used $\mathrm{BaCO}_{3}$ and $\alpha-\mathrm{Fe}_{2} \mathrm{O}_{3}$ powders which are homogeneously mixed resulting an assembly according to figure 1. 


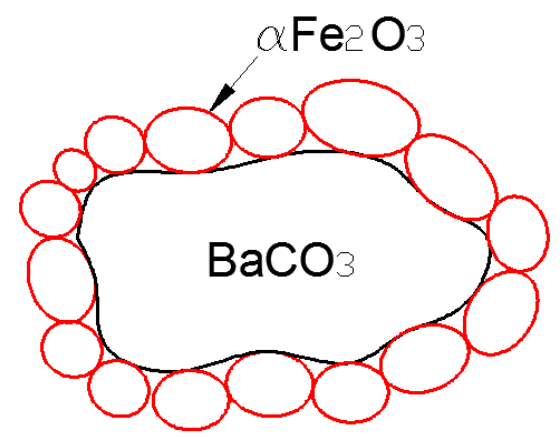

Fig. 1 Homogeneous mixture $\mathrm{BaCO}_{3} \times 6 \alpha-\mathrm{Fe}_{2} \mathrm{O}_{3}$

As shown in the homogeneous mixture image, hematite particles being much finer than those of $\mathrm{BaCO}_{3}$ are spread as a powder on the barium carbonate pellet, increasing in this way the number of contact points at mixture heating for the ferrite formation. For this reason, the morphology of the powder granules, especially of hematite, is important for the formation of ferrite.

Therefore, an influence factor that will be studied in this paper is the effect of $\mathrm{Fe}_{2} \mathrm{O}_{3}$ mechanical milling at heating of the homogeneous stoichiometric mixture $\mathrm{BaCO}_{3} \times 6 \alpha-\mathrm{Fe}_{2} \mathrm{O}_{3}$.

\section{Materials and experimental procedure}

The barium hexaferrites samples were obtained by a ceramic technique. So, for formation of $\mathrm{BaFe}_{12} \mathrm{O}_{19}$, mixture of iron oxide $\mathrm{Fe}_{2} \mathrm{O}_{3}\left(99,56 \%\right.$ purity) and barium carbonate $\mathrm{BaCO}_{3}(99,38 \%$ purity) powders was used with composition $1 \mathrm{BaCO}_{3}+6 \mathrm{Fe}_{2} \mathrm{O}_{3}$.

There have been developed three types of mixtures, presented in table 1, for barium hexaferrites formation and were coded as follows:

$\mathrm{SM}$ - homogeneous mixture composed by $\mathrm{BaCO}_{3}$ and $\alpha-\mathrm{Fe}_{2} \mathrm{O}_{3}$ powders;

$5 \mathrm{SM}$ - homogeneous mixture composed by $\mathrm{BaCO}_{3}$ and $\alpha-\mathrm{Fe}_{2} \mathrm{O}_{3}$ powders obtained after 5 hours of milling;

20SM - homogeneous mixture composed by $\mathrm{BaCO}_{3}$ and $\alpha-\mathrm{Fe}_{2} \mathrm{O}_{3}$ powders obtained after 20 hours of milling.

Table 1 Defining mixtures for experiments

\begin{tabular}{|c|c|c|c|}
\hline No. & Mixtures & Mixture codes & Mixture details \\
\hline 1 & $6 \mathrm{Fe}_{2} \mathrm{O}_{3}+\mathrm{BaCO}_{3}$-homogenized & $\overline{\mathrm{SM}}$ & \multirow{3}{*}{$\begin{array}{l}\text { Homogeneous mixtures } \\
\text { carried out in a ball mill } \\
\text { Pulverisette } 6 \text { in dry } \\
\text { conditions }\end{array}$} \\
\hline 2 & $\begin{array}{c}\left(6 \mathrm{Fe}_{2} \mathrm{O}_{3}-5 \mathrm{~h}\right)+\mathrm{BaCO}_{3}- \\
\text { homogenized }\end{array}$ & $5 \mathrm{SM}$ & \\
\hline 3 & $\begin{array}{c}\left(6 \mathrm{Fe}_{2} \mathrm{O}_{3}-20 \mathrm{~h}\right)+\mathrm{BaCO}_{3^{-}} \\
\text {homogenized }\end{array}$ & 20SM & \\
\hline
\end{tabular}

Mechanical milling process of the $\alpha-\mathrm{Fe}_{2} \mathrm{O}_{3}$ was carried out in a vibratory mill type PULVERISETTE 4 for 5 and 20 hours in wet atmosphere. The weight ratio of balls to milled material was $2: 1$. After milling process the powders were dryed in a rezistive oven at $200^{\circ} \mathrm{C}$ for 30 minutes. Further, the powders were disagglomerated in a ball mill for 3 minutes in air atmosphere. The obtained powders were analyzed by particles size distribution point of view using a BROOKHAVEN 90PLUS device. The mixtures from table 1 were homogenized in a planetary ball mill PULVERISETTE 6 for 40 minutes.

In order to determinate the barium hexaferrite we used a derivatograph device to heat the mixtures up to $1500^{\circ} \mathrm{C}$ in air atmosphere. Phase identification of the samples was carried out by Xray diffractometer (D8 Discover (Bruker)) in $\theta-2 \theta$ geometry using $\mathrm{Cu} \mathrm{K} \alpha$ radiation of wavelength $1.5418 \AA$ and a step size of $0.05^{\circ}$. 


\section{Results and discussions}

\section{Developing mixtures for experiments}

In order to elaborate the mixture for research, it was started with the mechanical milling of $\alpha$ $\mathrm{Fe}_{2} \mathrm{O}_{3}$ initial powders for 5 and 20 hours using a planetary ball mill Pulverisette 4 .

$\mathrm{Fe}_{2} \mathrm{O}_{3}$ powders obtained after milling were characterized by morphological point of view determining the aspect of powder granules by TEM microscopy (fig. 2) and the particle size distribution using a BROOKHAVEN BI-90 PLUS MAS device which is based on laser light scattering method of the particles in suspension. Thus, in fig. 3 are presented the particle size distributions of hematite powder after milling 5 and 20 hours.

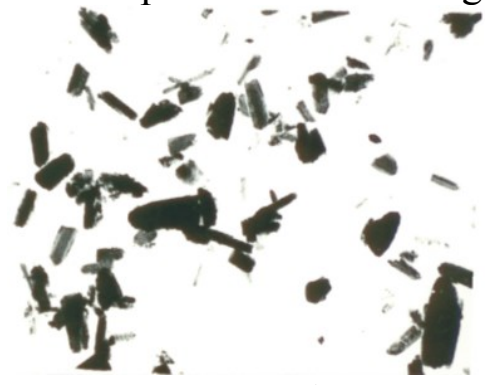

a)

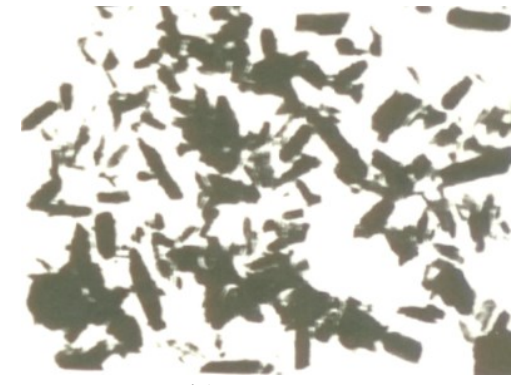

b)

Fig. 2 Microscopic aspect of hematite granules after:

a) 5 hours of milling; b) 20 hours of milling

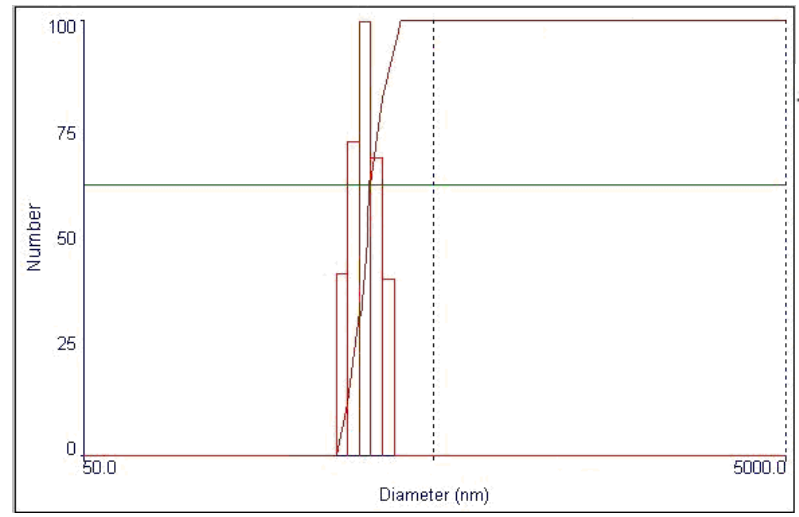

\begin{tabular}{ccc|ccccccc}
$\mathrm{d}(\mathrm{nm})$ & $\mathrm{G}(\mathrm{d})$ & $\mathrm{C}(\mathrm{d})$ & $\mathrm{d}(\mathrm{nm})$ & $\mathrm{G}(\mathrm{d})$ & $\mathrm{C}(\mathrm{d})$ & $\mathrm{d}(\mathrm{nm})$ & $\mathrm{G}(\mathrm{d})$ & $\mathrm{C}(\mathrm{d})$ \\
\hline 200.7 & 0 & 0 & 462.3 & 0 & 94 & 1064.9 & 0 & 94 \\
216.5 & 0 & 0 & 498.7 & 0 & 94 & 1148.8 & 0 & 94 \\
233.6 & 0 & 0 & 538.0 & 0 & 94 & 1239.3 & 0 & 95 \\
252.0 & 0 & 0 & 580.4 & 0 & 94 & 1337.0 & 0 & 97 \\
271.8 & 0 & 12 & 626.2 & 0 & 94 & 1442.3 & 0 & 99 \\
293.3 & 0 & 33 & 675.5 & 0 & 94 & 1556.0 & 0 & 99 \\
316.4 & 0 & 62 & 728.7 & 42 & 94 & 1678.6 & 0 & 100 \\
341.3 & 0 & 82 & 786.2 & 72 & 94 & 1810.9 & 0 & 100 \\
368.2 & 0 & 94 & 848.1 & 100 & 94 & 1953.6 & 0 & 100 \\
397.2 & 0 & 94 & 915.0 & 68 & 94 & 2107.5 & 0 & 100 \\
428.5 & 0 & 94 & 987.1 & 40 & 94 & 2273.6 & 0 & 100
\end{tabular}

a)

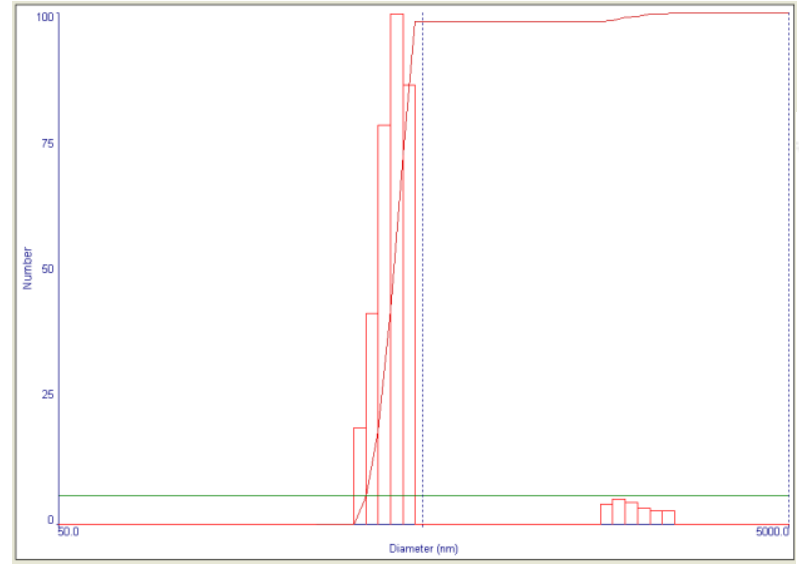

\begin{tabular}{rrr|rcc|rcc}
$d(n m)$ & $G(d)$ & $C(d)$ & $d(n m)$ & $G(d)$ & $C(d)$ & $d(n m)$ & $G(d)$ & $C(d)$ \\
\hline 50.1 & 0 & 0 & 201.6 & 0 & 95 & 810.9 & 0 & 100 \\
56.9 & 0 & 0 & 228.8 & 0 & 95 & 920.3 & 0 & 100 \\
69.6 & 20 & 0 & 259.7 & 0 & 95 & 1044.4 & 0 & 100 \\
73.3 & 43 & 54 & 294.7 & 4 & 95 & 1185.2 & 0 & 100 \\
83.2 & 78 & 85 & 334.5 & 5 & 96 & 1345.1 & 0 & 100 \\
94.4 & 100 & 95 & 379.6 & 4 & 97 & 1526.5 & 0 & 100 \\
107.1 & 85 & 95 & 430.8 & 3 & 100 & 1732.4 & 0 & 100 \\
121.6 & 0 & 95 & 488.9 & 2 & 100 & 1966.0 & 0 & 100 \\
138.0 & 0 & 95 & 554.8 & 2 & 100 & 2231.1 & 0 & 100 \\
156.6 & 0 & 95 & 629.6 & 0 & 100 & 2532.0 & 0 & 100 \\
177.7 & 0 & 95 & 714.5 & 0 & 100 & 2873.5 & 0 & 100
\end{tabular}

b)

Fig. 3 Particle size distributions of hematite powders after:

a) 5 hours of milling; b) 20 hours of milling

TEM analysis results highlight the fact that powder particles after milling presents in both cases acicular shape. 
In table 2 are summarized the granulometric analysis results of the hematite powders used in mixtures for the development of barium hexaferrites and the dimensional maxim of the powder granules are shown in figure 4 :

Table 2 Particles size distribution of hematite powders

\begin{tabular}{|c|c|c|c|}
\hline No. & Hematite powders & $\begin{array}{c}\text { Granulometric } \\
\text { ranges }[\boldsymbol{\mu m}]\end{array}$ & $\begin{array}{c}\text { Maximum size of particles } \\
{[\boldsymbol{\mu m}]}\end{array}$ \\
\hline 1 & $\mathrm{Fe}_{2} \mathrm{O}_{3}$ initial powder & {$[1.55-2.42]$} & 2.03 \\
\hline 2 & $\mathrm{Fe}_{2} \mathrm{O}_{3}$ milled 5 hours & {$[0.72-0.98]$} & 0.84 \\
\hline 3 & $\mathrm{Fe}_{2} \mathrm{O}_{3}$ milled 20 hours & $\begin{array}{c}{[0.29-0.55]} \\
{[0.069-0.10]}\end{array}$ & 0.094 \\
\hline
\end{tabular}

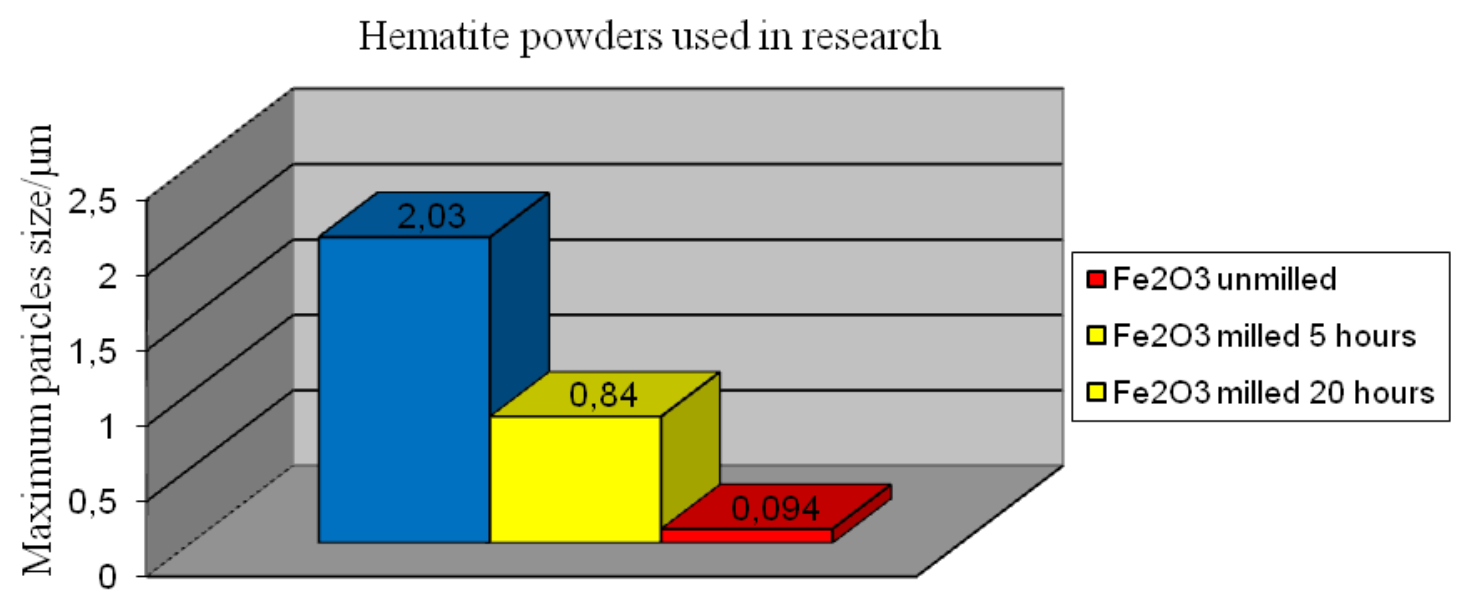

Fig. 4 The maximum particles size of hematite powders

According to the data from table 2 and figure 4 we are able to present the following conclusions:

- After 5 hours of $\mathrm{Fe}_{2} \mathrm{O}_{3}$ milling appears a representative granulometric fraction in the size range of [0.72-0.98] $\mu \mathrm{m}$ where the dimensional maximum is placed at the value of $0.84 \mu \mathrm{m}$;

- After 20 hours of $\mathrm{Fe}_{2} \mathrm{O}_{3}$ milling there are appearing on the granulometric sheet two ranges, the first is within [0.069-0.10] $\mu \mathrm{m}$ and the second range is within [0.29-0.55] $\mu \mathrm{m}$, maximum value being at $0.094 \mu \mathrm{m}$.

Therefore, it should be mentioned that if for SM standard mixture were used powders with micron grain size, in the case of the 5SM and 20SM mixtures the majority granulation of hematite powders is in the submicron domain.

\section{Thermogravimetric analysis of the mixtures}

In order to reduce the synthesis temperature of the barium hexaferrite were used in mixtures $\alpha-\mathrm{Fe}_{2} \mathrm{O}_{3}$ milled powder in wet conditions for 5 to 20 hours.

The main problem of the ceramic compounds consists in the high temperature at which the ferrite formation process is finalized. This fact leads to high energy consumption, time and premature degradation of the heating furnaces.

For this reason, in the research was studied the $\alpha-\mathrm{Fe}_{2} \mathrm{O}_{3}$ granulation influence on the firing temperature of hexaferrite. In this sense, there have been studied the 5SM and 20SM mechanical mixtures formed by barium carbonate and hematite powders resulted by milling of initial hematite for 5 and 20 hours.

The significantly peaks after heating, from obtained diagrams, were analyzed by heating another sample up to the maximum intensity of the peak and then quickly cooled in water. In order to see what kind of compound is presented at that peak it was used the X-ray diffraction analysis. 
So, in figure 5 is shown the diagram for 5SM stoichiometric homogeneous mixture at heating.

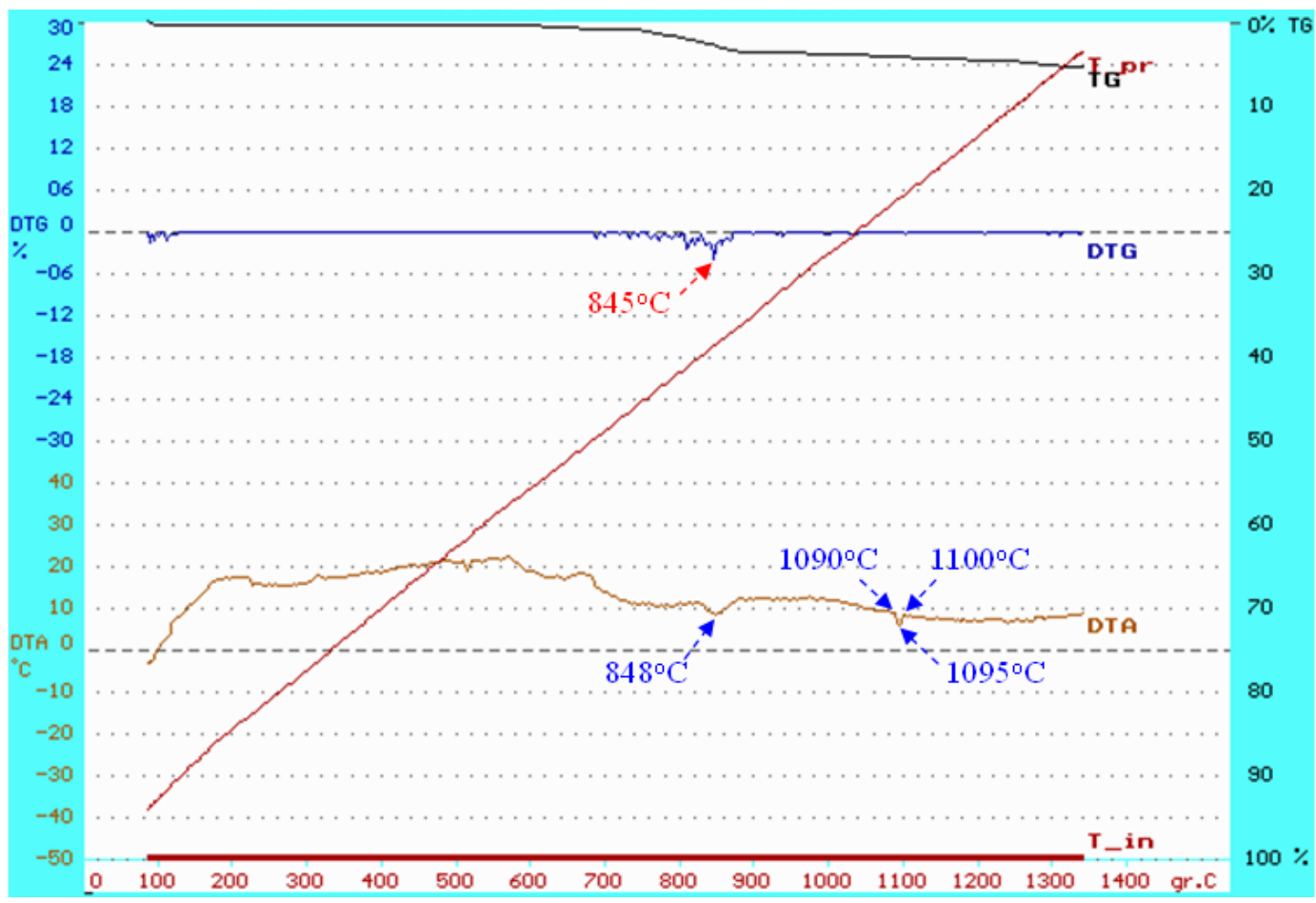

Fig. 5 Diagram for 5SM mixture

In this diagram it can be observed on the TG and DTG curves a weight loss of the sample in the temperature range (750-880) ${ }^{\circ} \mathrm{C}$. The total loss in weight of the sample is $5 \%$ of the initial weight.

On the DTA curve makes its appearance a peak at $848^{\circ} \mathrm{C}$ which according to the diffractogram from figure 6 corresponds to the formation of barium monoferrite. At the temperature of $1095^{\circ} \mathrm{C}$ we identify on the DTA curve a maximum corresponding to a new peak which according to the diffractogram from figure 7 corresponds to the formation of barium hexaferrite.

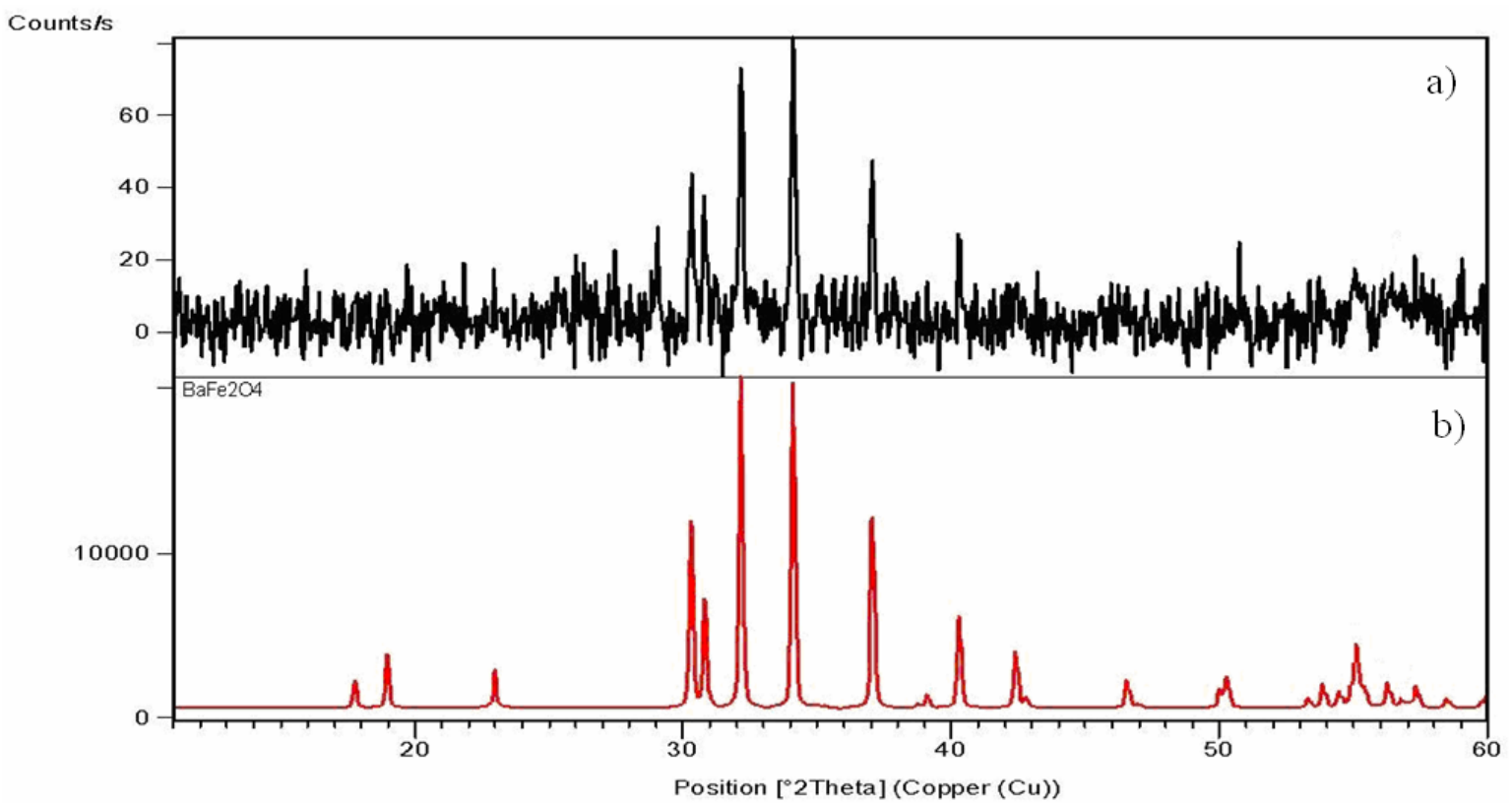

Fig. 6 Diffractogram of the $5 \mathrm{SM}$ mixture heated up to $848^{\circ} \mathrm{C}$ : a) sample; b) monoferrite 


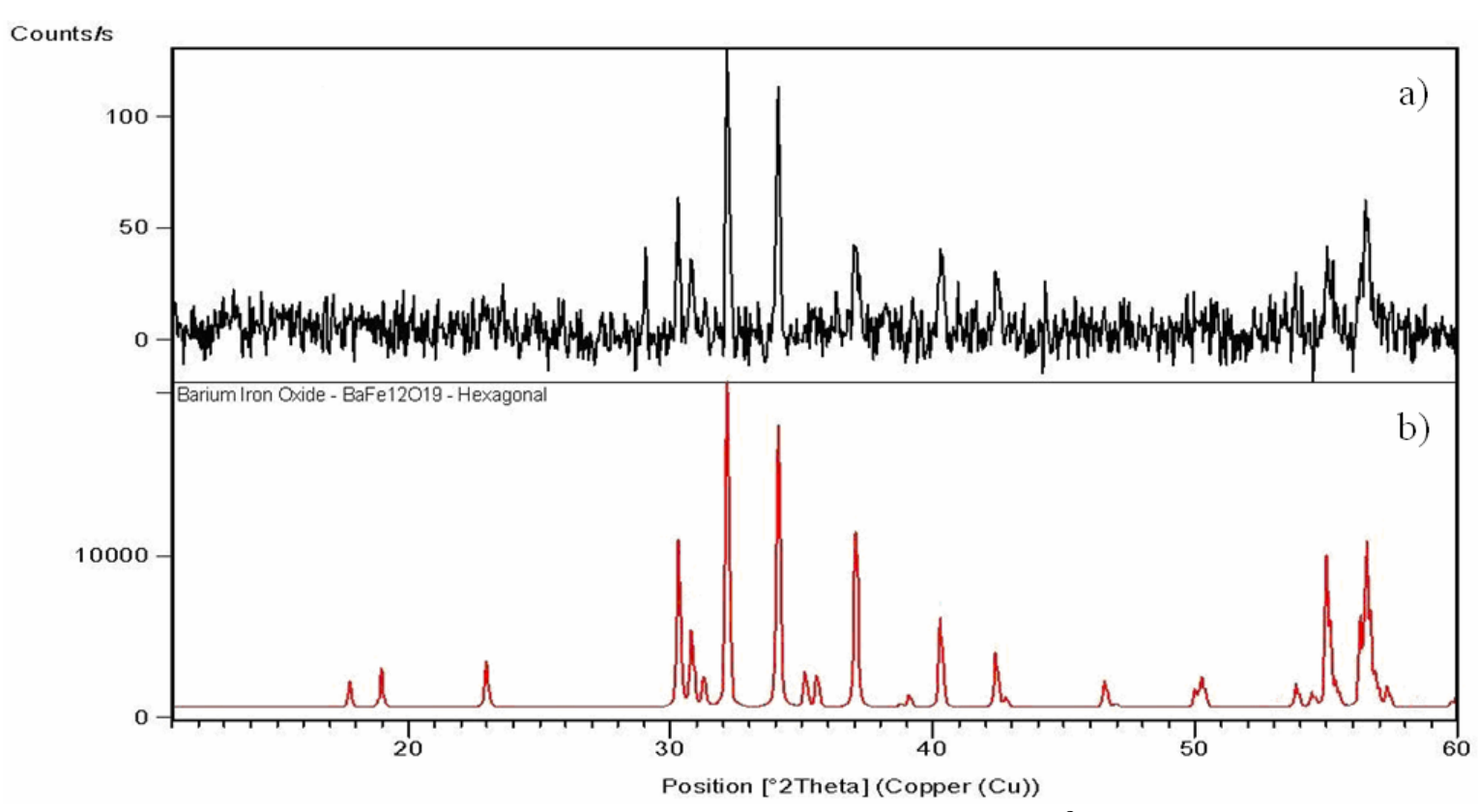

Fig. 7 Diffractogram of the $5 \mathrm{SM}$ mixture heated up to $1095^{\circ} \mathrm{C}$ : a) sample; b) hexaferrite

In figure 8 is drawn the diagram for 20SM homogeneous mixture after heating.

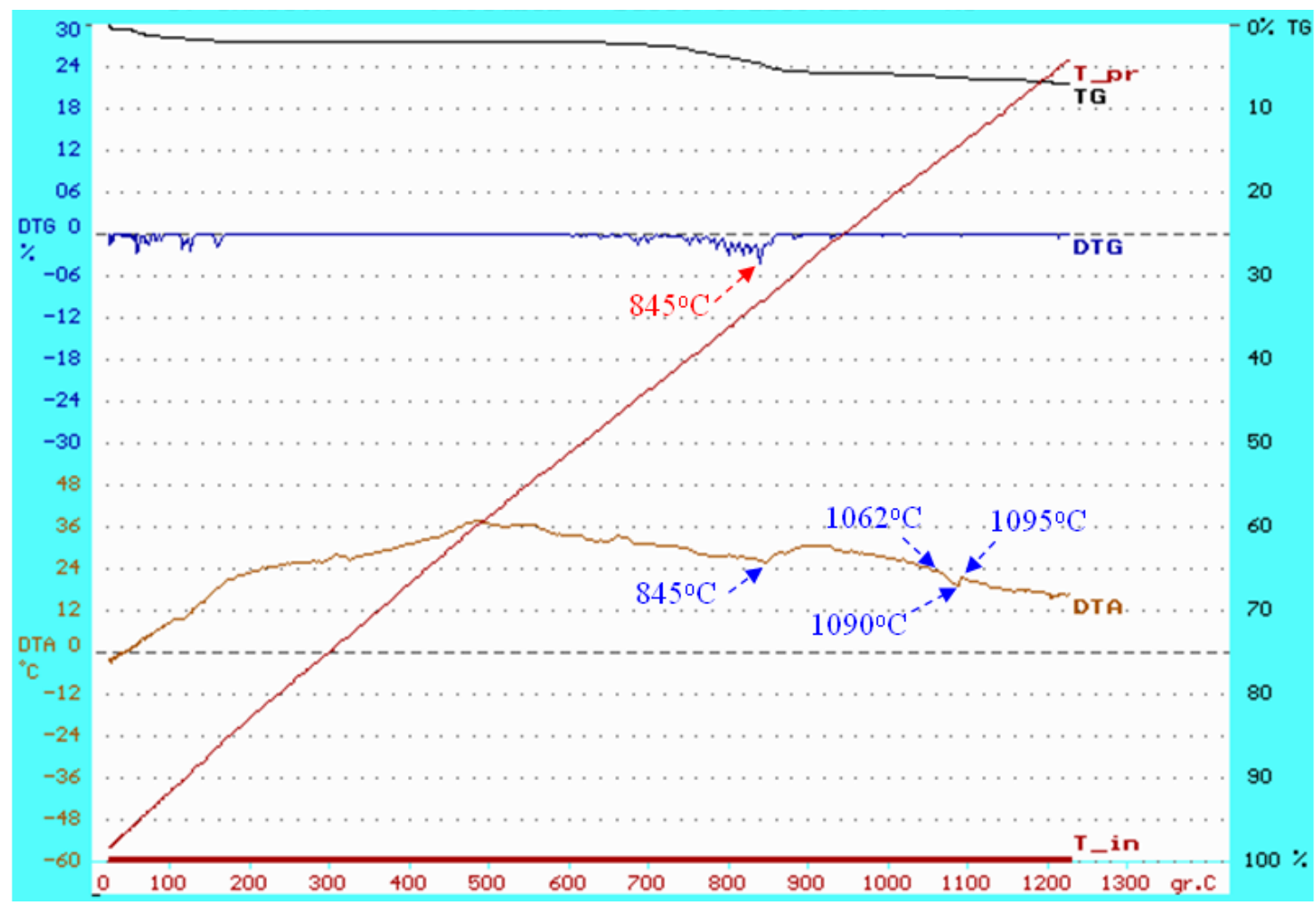

Fig. 8 Diagram for 20SM mixture

The significant peaks in this diagram are at $845^{\circ} \mathrm{C}$ specific to barium monoferrite, the other significant peak is at $1090^{\circ} \mathrm{C}$ and according to the diffractogram from figure 9 this peak corresponds to the maximum intensity of the reaction for the formation of barium hexaferrite.

According to the TG curve total weight loss of the sample is $7 \%$. 


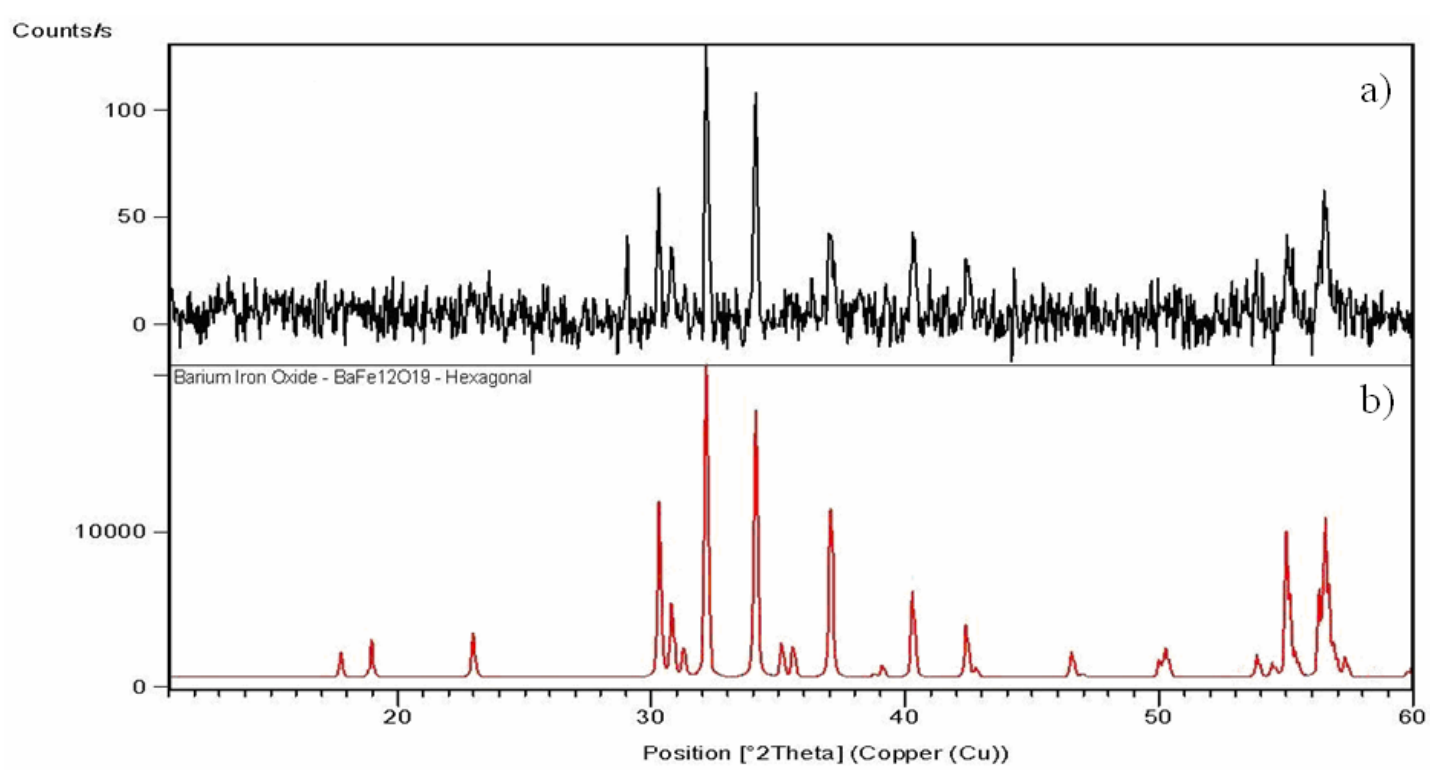

Fig. 9 Diffractogram of the 20SM mixture heated up to $1090^{\circ} \mathrm{C}$ : a) sample; b) hexaferrite

Based on the data from diagrams, was plotted the chart in figure 10 which presents the intensity of barium ferrite type $\mathrm{M}$ formation temperature, depending on the nature of the mixture.

Synthesis temperature of barium hexaferrite

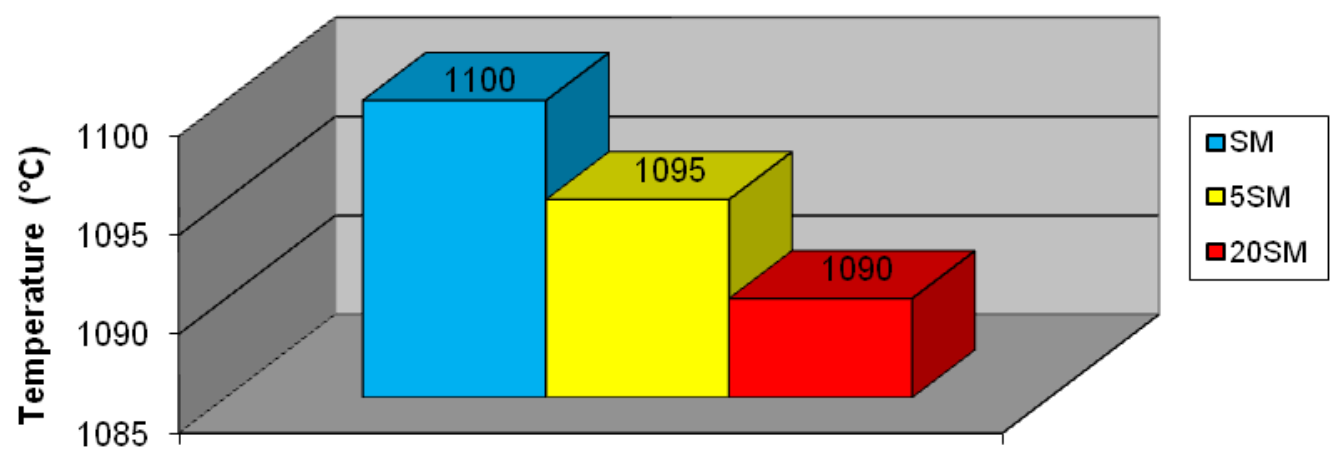

Fig. 10 Heating temperature range to barium hexaferrite synthesis

Analyzing the graph we find that hexaferrite formation is favored by increasing of fineness hematite powder. The decreases of firing temperature can be explained by increasing the number of the contact points between the small particles of hematite and $\mathrm{BaCO}_{3}$ particle according to the diagram from figure 1 .

\section{Conclusions}

The results regarding mechanical milling of $\mathrm{Fe}_{2} \mathrm{O}_{3}$ indicated that the granulation of hematite powders decreased with the increase of milling time, starting from micronic to nanometric domain. So, the granulation of $\mathrm{Fe}_{2} \mathrm{O}_{3}$ milled powders for 20 hours decreased up to $95 \%$ compared with the $\mathrm{Fe}_{2} \mathrm{O}_{3}$ unmilled powders. It can be observed that the firing temperature of the hexaferrite decreases with 10 degrees by introduction of the milled hematite powders in the mixtures. Therefore, one of the possibilities to reduce the firing temperature of hexaferrite is to use fine hematite powder in the mixture. 


\section{References}

[1] P. Winotaia, S. Thongmeea, I.M. Tang, Cation distribution in bismuth-doped M-type barium hexaferrite, Materials Research Bulletin 35 (2000) 1747-1753;

[2] Jacobo S.E., Civale L., Domingo-Pascual C., Rodrigues-Clements R., Blesa M.A., J. Mater. Sci. 32 (1997) 1025, 216;

[3] O. Carp, R. Barjega, E. Segal, M. Brezeanu, Thermochim. Acta 318 (1998) 57;

[4] T. Ogasawara, M.A.S. Oliveira, J. Magn. Magn. Mater. 217 (2000) 147;

[5] J. Matutes-Aquino, S. Diaz-Castanon, M. Mirabal-Garcia, S.A. Palomares-Sanchez, Scripta Mater. 42 (2000) 295;

[6] P. Shepherd, K. Mallick, J. Roger, Green Magnetic and structural properties of M-type barium hexaferrite prepared by co-precipitation, Journal of Magnetism and Magnetic Materials 311 (2007) 683-692;

[7] E. Rezlescu, L. Rezlescu, P.D. Popa, N. Rezlescu, $\mathrm{BaFe}_{12} \mathrm{O}_{19}$ fine crystals dispersed in a glassy matrix: magnetic and structural propert, Materials Science and Engineering A 375-377 (2004) 1269-1272;

[8] M. Drofenik, and K. Matjaz, Hydrothermal Synthesis of Ba-Hexaferrite Nanoparticles, J. Am. Ceram. Soc., 90 [7] (2007) 2057-2061;

[9] Li Kang, Gu Hongchen and Wei Qun, A novel hydrothermal synthesis method for barium ferrite, China Particuology, Vol. 2, No. 1, (2004) 41-43;

[10] W. Zhong, W. Ding, N. Zhang, J. Hong, Q. Yan, Y. Du, Key step in synthesis of ultrafine $\mathrm{BaFe}_{12} \mathrm{O}_{19}$ by sol-gel technique, J. Magn. Magn. Mater. (1997)168;

[11] Li Hui, Jie Huang, Li Qingfeng, Su Xiaodong, Preparation of barium ferrite films with high Fe/Ba ratio by sol-gel method, J Sol-Gel Sci Technol (2009) 52:309-314;

[12] A. Mali, A. Ataie, Structural characterization of nanocrystalline $\mathrm{BaFe}_{12} \mathrm{O}_{19}$ powders synthesized by sol-gel combustion route, Scripta Materialia 53 (2005) 1065-1075;

[13] V. Pillai, P. Kumar, M.S. Multani, D.O. Shah, Structure and magnetic properties of nanoparticles of barium ferrite synthesized using microemulsion processing, Colloids and Surfaces A: Physicochemical and Engineering Aspects, Vol. 80, Issue 1, 26 (1993), 69-75;

[14] V. V. Molchanov, R. A. Buyanov, Yu. T. Pavlyukhin, Effect of Mechanochemical Activation on the Catalytic Properties of Ferrites with the Spinel Structure, Kinetics and Catalysis, Vol. 44, Issue 6, (2003)788-792;

[15] I. Ştefan, C. Nicolicescu, A. Olei, Thermogravimetric studies on the BHF synthesis of $\mathrm{BaCO}_{3}$ and $\alpha-\mathrm{Fe}_{2} \mathrm{O}_{3}$ mixtures processed by mechanical alloying, J. of opt. and adv. Mat. Vol. 15, No. 78, (2013) $774-780$. 